\title{
Uncovering the influence of social skills and psychosociological factors on pain sensitivity using structural equation modeling
}

This article was published in the following Dove Press journal: Journal of Pain Research

II September 2017

Number of times this article has been viewed

\author{
Yoichi Tanaka ${ }^{1,2}$ \\ Yuki Nishi' \\ Yuki Nishi' \\ Michihiro Osumi ${ }^{3}$ \\ Shu Morioka ${ }^{1,3}$ \\ 'Department of Neurorehabilitation, \\ Graduate School of Health Sciences, \\ Kio University, ${ }^{2}$ Department of \\ Rehabilitation, Nara Prefecture \\ General Rehabilitation Center, \\ ${ }^{3}$ Department of Neurorehabilitation \\ Research Center, Kio University, \\ Nara, Japan
}

\begin{abstract}
Pain is a subjective emotional experience that is influenced by psychosociological factors such as social skills, which are defined as problem-solving abilities in social interactions. This study aimed to reveal the relationships among pain, social skills, and other psychosociological factors by using structural equation modeling. A total of 101 healthy volunteers ( 41 men and 60 women; mean age: $36.6 \pm 12.7$ years) participated in this study. To evoke participants sense of inner pain, we showed them images of painful scenes on a PC screen and asked them to evaluate the pain intensity by using the visual analog scale (VAS). We examined the correlation between social skills and VAS, constructed a hypothetical model based on results from previous studies and the current correlational analysis results, and verified the model's fit using structural equation modeling. We found significant positive correlations between VAS and total social skills values, as well as between VAS and the "start of relationships" subscales. Structural equation modeling revealed that the values for "start of relationships" had a direct effect on VAS values (path coefficient $=0.32, p<0.01$ ). In addition, the "start of relationships" had both a direct and an indirect effect on psychological factors via social support. The results indicated that extroverted people are more sensitive to inner pain and tend to get more social support and maintain a better psychological condition.
\end{abstract}

Keywords: social skills, psychosociological factors, pain sensitivity

\section{Introduction}

Pain is a subjective experience and is caused not only by physical damage but also emotional $^{1}$ or cognitive aspects (e.g., attention, and expectation). ${ }^{2,3}$ Therefore, the sensitivity of pain varies among individuals even for the same intensity of stimulation; previous studies have suggested that individual evaluation and intervention are necessary in clinical practice. Meanwhile, pain can be induced simply by observing painful scenes in photographs. ${ }^{4-6}$ Observations of painful scenes activated the brain area that was related to the pain matrix, and the observation was thought to be useful for creating experimental pain emotion without the influence of peripheral organ. ${ }^{7,8}$

The biopsychosocial model is proposed as the framework for understanding the concept of complex treatment for pain. ${ }^{9}$ This model stresses the importance of the psychological and social aspects, which reflect emotions, feelings, and the role of the self in the social environment and society surrounding the person of object, in addition to a biological factor due to the physical damage.

The relationship between pain and social aspects has attracted attention in recent years. For example, Macdonald et $\mathrm{al}^{10}$ reported that social pain is induced by exclu-
Correspondence: Yoichi Tanaka Department of Neurorehabilitation, Graduate School of Health Sciences, Kio University, 4-2-2 Umami-naka, Koryo-cho, Kitakatsuragi-gun, Nara 635-0832, Japan

Tel $+8|74554| 60 \mid$

Fax +8I 745541600

Email kempt_24am@yahoo.co.jp 
sion or low evaluation in a close relationship (e.g., a friend, lover, or family member). In social pain, the frustration of basic desires, which includes the so-called position desire and good relationships with others, induces social pain as an alarm reaction. ${ }^{11-13}$ Eisenberger has reported that social pain and physical pain have a common neural mechanism. ${ }^{14}$ Furthermore, the sensitivity of the social pain and the sensitivity of the physical pain were shown to be positively correlated, ${ }^{14,15}$ and it is thought that the person who is sensitive to social pain is also sensitive to physical pain. In this way, it has been revealed that social pain has similar neural process as physical pain, and it is thought that the social environment surrounding an individual modulates the pain sensitivity. ${ }^{16,17}$ It is known that such social environments have a direct influence on physical pain, and the quality of the relationship with a close friend has been reported to modulate the physical pain sensitivity. ${ }^{18}$ In addition, it has been revealed that physical pain is reduced by social support (e.g., gentle words, existence of a partner, clenching the hand of others). ${ }^{19-22}$ In this way, it has been revealed that sensitivity of the pain is low in the person who builds good social relations and has good support from those around him/her. However, loneliness in cancer patients exacerbated psychological conditions such as depression and perception of pain; ${ }^{23}$ depression and anxiety can also increase physical pain sensitivity. ${ }^{24,25}$ Thus, interactions with one's social environment is critical for managing pain; social skills are among the personal characteristics required for adequate social interaction.

Social skills are defined as the ability to effectively interact with other people. ${ }^{26}$ This skill comprises aspects of verbal and nonverbal communication and includes styles of social problem solving (e.g., rational, impulsive, and avoidant), confidence, assertiveness, goal direction, and self-monitoring. ${ }^{27}$ In previous studies, it has been reported that depression and loneliness are high in people with low social skills. ${ }^{28-30}$ In addition, people who have high social skills can readily receive social support, and they tend not to find themselves in extremely difficult states. ${ }^{31}$ Additionally, in previous studies using structural equation modeling, people whose social skills are high have been found to have high social support as well as quality of life, and they did not fall into depression. ${ }^{32}$ In this way, it has been revealed that social skills influence the formation and construction of personal psychosociology (social support, depression, loneliness). ${ }^{28-31}$ In addition, it was found that social support reduces pain sensitivity ${ }^{19-22}$ and that negative psychological condition increases pain sensitivity. ${ }^{23-25}$ However, there are no studies that have examined relations between social skills and pain sensitivity and that have examined mutual relationships between psychosociological factors and pain sensitivity. Therefore, the aim of this study was to examine 1) the relations between social skills and pain sensitivity and 2) the influence of social skills and psychosociological factors on pain sensitivity, using structural equation modeling.

\section{Materials and methods Ethics statement}

The experimental protocol was approved by the Kio University Ethics Committee (approval number: H26-31), and the study protocol conformed to the Declaration of Helsinki. Participants provided written consent to participate in the experiment after receiving an explanation of the procedures involved.

\section{Participants}

This study was carried out from October 2014 to June 2015. The participants were recruited from three organizations to ensure variations in age and type of occupation (medical institution, general company, university). Exclusion criteria were chronic or acute pain, current psychiatric diagnosis, or use of anxiolytics or antidepressants. The participants were all volunteers, and no entrance fee was paid. They were 101 healthy volunteers (41 men and 60 women; mean age: $36.6 \pm 12.7$ years); 41 were in health care occupations, 38 were in other types of work, 21 were university students, and 1 was unemployed.

Sample size for this exploratory study was calculated using the computer program $\mathrm{G}^{*}$ Power prior to data collection. We calculated the sample size necessary for a correlation analysis with the effect size used in a previous study (effect size $=0.3$ power $=0.8) .{ }^{33}$ Using these parameters, the recommended sample size was 82 ; we aimed to recruit a few more participants than this sample size. Since some of the previous studies used more than 100 samples in the structural equation modeling, ${ }^{34-36}$ we decided the final sample size in reference to these works.

\section{Procedure}

In this study, we used an inner experience of pain as the pain stimulation. This decision was made because it is relatively easier to collect samples without the risk associated with violence or physical aggression. After administering an inner experience of pain to each subject, we performed the autocriticism task for each question. 


\section{Pain stimulation}

The inner experience of pain was proposed by Ogino et al, ${ }^{7}$ and the subjective feeling of pain is said to occur because of such an inner experience.

The task was performed in a block design, and a total of three sets were carried out. One set consisted of 10 trials, and 1 trial consisted of 1 second of fixation on an image of a cross, followed by a 2-second fixation on an image showing a painful event, and then a 2-second fixation on a blank white page (Figure 1). The images showing painful events were those used in a previous study by the authors. ${ }^{5,7}$ Examples of images of painful events are shown in Figure 2. This was the frequently used approach in the previous studies. ${ }^{37,38} \mathrm{We}$ used eight kinds of pain images (e.g., "I cut a finger with a kitchen knife," "A needle on the finger stings") involving both the left and the right hands. The images were angled so that they allowed for the participant to feel as though the painful events were happening to him/her. To evoke the participants' sense of inner pain, we showed them images of painful events on a PC screen and asked them to evaluate the intensity of pain using the VAS. We then calculated the mean VAS of the three sets of images.

\section{Measures}

\section{Visual analog scale}

A $10 \mathrm{~cm}$ VAS was provided for participants to rate their current level of pain, which was assessed after each set of inner experience tasks. The VAS is a psychometric scale along a continuous line that measures subjective pain levels. The scale ranges from " 0 " or "none," indicating no pain, to " 10 " or "agonizing," indicating severe pain. The advantage of the VAS is its simplicity, which allows quick and intuitive answers from patients. ${ }^{39,40}$

\section{Social Skills Self-Rating Scale for Adults}

Because social skills are affected by culture and nationality, we used the Social Skills Self-Rating Scale for Adults designed to evaluate social skills in Japan. ${ }^{41}$ This self-rating scale is a standard measure that can simultaneously assess concrete and communication skills in an interpersonal interaction. ${ }^{41}$ It comprises six subscales: "start of relationships," "decoding," "claim," "control of feelings," "maintenance of relationships," and "encoding." The scale consists of 35 items, including four reversed items. An example of an item in the 8-item "start of relationships" subscale is "You're

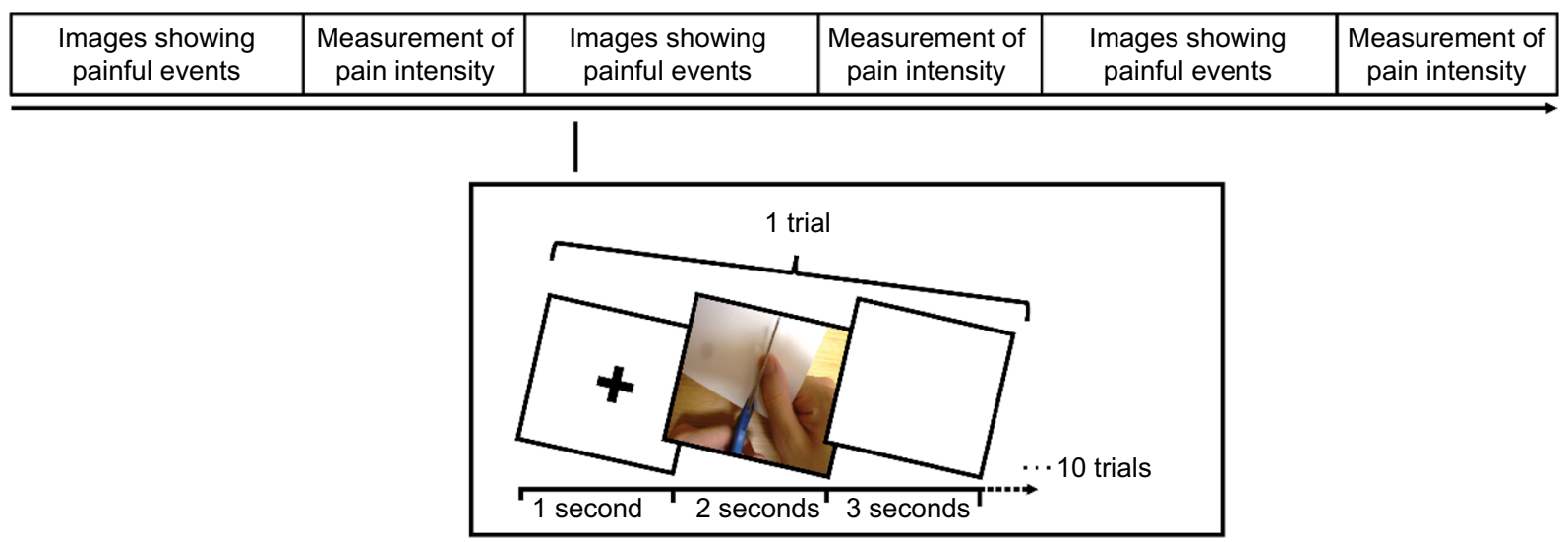

Figure I Pain stimulation procedure.

Notes: The experiment consisted of three sets. The subjects evaluated the pain intensity at the end of each set. One set consisted of I0 trials, and I trial consists of I second of fixation on an image of a cross, followed by a 2-second fixation on an image showing a painful event, and then a 2-second fixation on a blank white page.
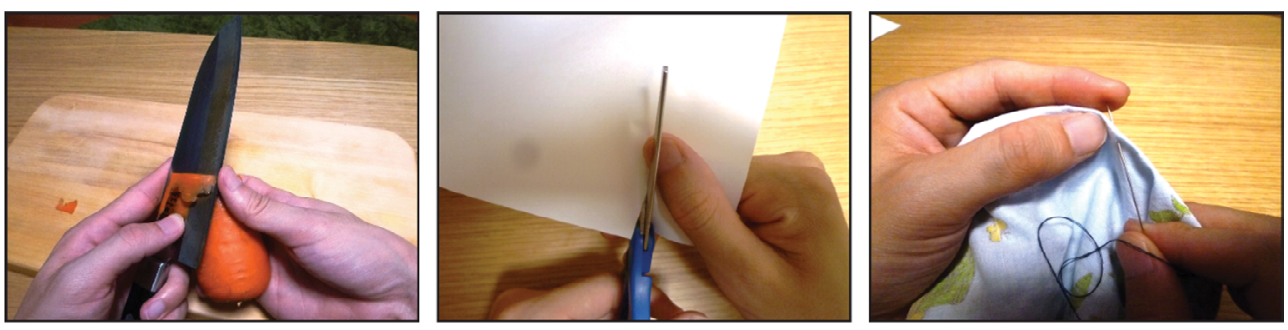

Figure 2 Sample painful images.

Notes: We used eight kinds of pain images involving both the left and the right hands. The images were angled so that they allowed for the participant to feel as though the painful events were happening to him/her. 
friendly with anyone." An example of an item in the 8-item "decoding" subscale is "You read a person's feelings from one's look." An example of an item in the 7-item "claim" subscale is "When your friend hurts your feelings, you tell your feelings clearly." An example of an item in the 4-item "control of feelings" subscale is "It's difficult to control your feelings." An example of an item in the "maintenance of relationships" subscale is "You behave depending on the situation." An example of an item in the 4-item "encoding" subscale is "You express your feelings openly." The items were rated on a scale from 1 to 4 (1= "very strongly disagree" to $4=$ "very strongly agree"), with higher scores indicating higher social skills. The Social Skills Self-Rating Scale for Adults has demonstrated good reliability and validity. ${ }^{41}$

\section{Multidimensional Scale of Perceived Social Support}

Perceived social support was assessed with the 12-item Multidimensional Scale of Perceived Social Support (MSPSS), which measures global perceived support (e.g., "There is a special person around when I am in need"). ${ }^{42}$ The items were rated on a scale from 1 to 7 (1= "very strongly disagree" to $7=$ "very strongly agree"). Internal consistencies of the subscales and total scale were excellent (Cronbach's $\alpha=0.85-0.91$ ), and the scales had demonstrated strong test-retest stability over a 2 - to 3 -month interval $(r=0.72-0.85)$. The construct validity of the total MSPSS scale has been demonstrated through its significant negative correlation with depression. ${ }^{42}$

\section{Beck Depression Inventory}

Depression was measured with the Japanese version of the second edition of the Beck Depression Inventory (BDI-II). ${ }^{43}$ The BDI-II is a validated self-administered questionnaire evaluating how a patient feels and experiences things. ${ }^{44}$ It consists of 21 questions, each of which is scored on a scale ranging from 0 to 3 . All scores are added to provide a total score, with a maximum score of 36 . The total score gives an estimation of the severity of existing depression $(0-13=$ no depression, 14-19= mild depression, 20-28= moderately severe depression, 29-63= severe depression). The Japanese version of the BDI-II was developed by Kojima et $\mathrm{al}^{43}$ using a translation-backtranslation procedure to establish crosslanguage equivalence, and has been well validated with the general population as well as with a clinical sample.

\section{The Japanese Revised UCLA Loneliness Scale}

The revised University of California, Los Angeles (UCLA) Loneliness Scale-Japanese version was employed to measure loneliness. Russell created the UCLA Loneliness Scale based on his understanding that loneliness occurs from conditional perspectives and that loneliness is unidimensional. ${ }^{45,46}$

This scale was translated and revised by Moroi, ${ }^{47}$ tested with participants in their teenage years to those aged over 65 years, and then named the Japanese revised UCLA Loneliness Scale. An example of items is "You stand alone from other people," "There is none of the people knowing you well." The scale consists of 20 items including 10 reversed items. The items are rated on a scale from 1 to $4(1=$ "absolutely disagree" to 4= "very strongly agree").

\section{Data analyses}

Analyses were performed using Statistical Package for the Social Sciences (SPSS), version 19.0 (SPSS Inc., Chicago, IL, USA) and SEM was performed using SPSS Amos 19.0 (SPSS Inc.). Normality of distribution of data was determined by the Shapiro-Wilk test. Statistical analysis was conducted according to the following three-stage approach. First, Student's $t$-tests were conducted to examine differences between men and women on each measure. A one-way analysis of variance (ANOVA) test was conducted to compare between three types of occupations (health care occupations, other types of work, and university study) on measures of social skills, social support, loneliness, depression, or VAS. After the ANOVA test, results with significant variation were subjected to post hoc tests to compare the significant differences between the three types of occupations. The post hoc analyses were performed using the Bonferroni test. Second, the correlation between social skills (include the subscales) and VAS was examined using Pearson correlation analysis. As we paid attention to a relationship between social skills and VAS, we focused on those relationships and performed a correlation analysis. Finally, we constructed a hypothetical model based on the results from previous studies and the current correlation analysis results (Figure 3), and then we used structural equation modeling to

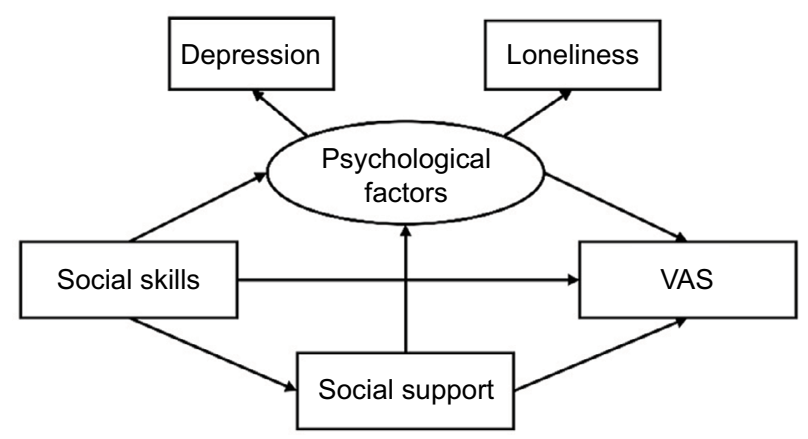

Figure 3 Hypothesized structural relationships between pain intensity and psychosociological factors (hypothesis model).

Abbreviation: VAS, visual analog scale. 
assess the model's fit with the data. We assessed data model fitness with the goodness-of-fit index (GFI), comparative fit index (CFI), and the root mean square error of approximation (RMSA). The goodness-of-fit was evaluated by the following criteria: GFI $>0.90$, CFI $>0.90$, and RMSEA $<0.05 .{ }^{48}$ Results of comparisons with a $p$-value of 0.05 or lower were considered to represent statistically significant differences. The method of Holm was used to adjust the $p$-values in multiple testing.

\section{Results}

\section{Descriptive statistics}

The participants were fairly evenly distributed across the age groups, except for the 55-65 age bracket: "15-24 years old” (21), "25-34 years old” (26), “35-44 years old” (23), "45-54 years old" (22), and "55-65 years old" (9). There were no statistically significant differences between men and women on the measures of "social skills" ( $p=0.23)$, social support ( $p=0.91)$, loneliness $(p=0.06)$, depression $(p=0.21)$, or VAS $(p=0.36)$. The results of ANOVA revealed a statistically significant difference in loneliness according to occupation as assessed by Japanese Revised UCLA Loneliness score $(F=3.775, p=0.02)$. The results of post hoc testing and loneliness scores in health care occupations were significantly higher than those found for the university students $(p=0.03)$.

\section{Correlation analysis}

Statistically significant positive correlations were observed between VAS and total social skills values, as well as between VAS and "start of relationships" subscales (Table 1). The VAS was most strongly correlated with the "start of relationships" subscale $(r=0.36, p<0.01)$.

\section{Covariance structure analysis of the hypothesized model}

The hypothesized model was constructed on the basis of a previous study ${ }^{25-29}$ and the result of the current correlational analysis involving total social skills values, VAS, social support, and psychological factors (depression, loneliness). The hypothesis model, with standardized path coefficients, is presented in Figure 4. The statistical goodness-of-fit of the hypothesis model, denoted by the $\chi^{2}$ value, was $0.448(d f=2$, $p=0.799$ ). The GFI was 0.998 , the CFI was 1.000 , and the RMSEA was 0.000 . The social skills had a meaningful negative influence on the psychological factors (path coefficient

Table I Correlations between social skills (including subscales) and pain intensity

\begin{tabular}{llllllll}
\hline & SS & SR & CF & EN & DE & MR & CL \\
VAS & $0.30^{*}$ & $0.36 * *$ & 0.24 & 0.22 & 0.15 & 0.17 & 0.00 \\
\hline
\end{tabular}

Notes: $* p<0.05, * * p<0.01$.

Abbreviations: CF, control of feelings; CL, claim; DE, decoding; EN, encoding; MR, maintenance of relationships; SR, start of relationships; SS, total social skills values; VAS, visual analog scale.

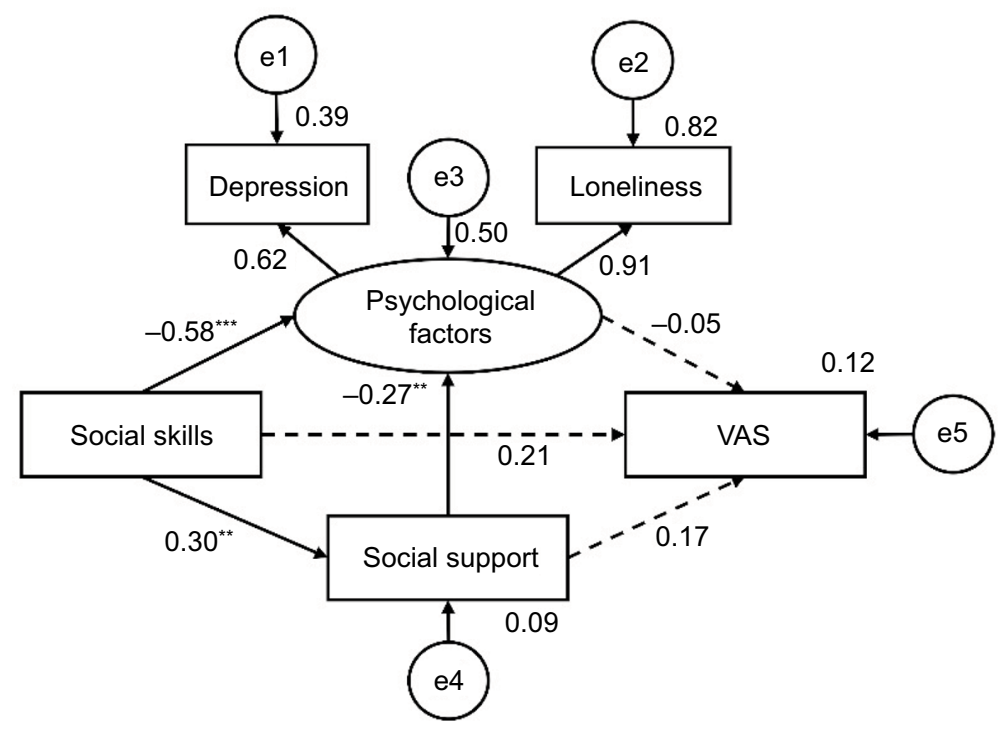

Figure 4 Hypothesized model (nonsignificant paths are indicated by dashed lines).

Notes: Model fit indices: $\chi^{2}=0.448, d f=2, p=0.799$, goodness-of-fit index $(G F I)=0.998$, comparative fit index $(C F I)=I .000$, root mean squared error of the approximation $($ RMSEA) $=0.000 ; * * p<0.01$, *** $p<0.001$.

Abbreviations: e, error; VAS, visual analog scale. 
$=-0.58, p<0.001$ )and positive influence on social support (path coefficient $=0.30, p<0.01$ ), and these findings affirmed those of a previous study. ${ }^{25-29}$ In addition, social skills had both a direct and an indirect effect on psychological factors via social support. However, the relation between social skills and VAS became apparent due to the direct effect of the social skills and not the indirect effects via psychological factors or via social support.

\section{Model adjusted by the covariance structure analysis}

We performed a model correction based on the results of the hypothesized model. The modified model, with standardized path coefficients, is presented in Figure 5. The statistical goodness-of-fit of the hypothesis model, denoted by the $\chi^{2}$ value, was 0.446 ( $d f=2, p=0.800)$. The GFI was 0.998 , the CFI was 1.000, and the RMSEA was 0.000 .

Since the influence of social skills on VAS did not become clear in the hypothesized model, we substituted "start of relationships" for social skills, as it had the highest correlation coefficient with VAS. The relationship between "start of relationships," social support, and psychological factors turned out to be similar to that found in the hypothesized model, and the direct positive influence of "start of relationships" on VAS became clear ( path coefficient $=0.32, p<0.01$ ).

\section{Discussion}

The correlational analysis in this study showed that pain intensity of inner experience was slightly related to high social skills. In addition, pain intensity was positively correlated with values of the subscales ("start of relationships") as well as with the total social skills scores. The structural equation model results indicated that in comparison to their peers with low scores on "start of relationships" (included in social skills subscale), participants whose score on "start of relationships" was high tended to receive more social support, had healthier psychological factors in the modified model, and more readily felt inner pain by observing painful scenes.

\section{Relationship between social skill and pain sensitivity}

To identify factor(s) that could predict pain sensitivity, we investigated the relationship between social skills and pain sensitivity. Results showed that pain sensitivity was positively correlated with social skills. In the previous study, social skills were found to be related to the ability to be empathetic. ${ }^{28}$ In addition, one's ability to be empathetic influenced his/her inner experience of pain from observations of painful scenes. ${ }^{49}$ Therefore, high social skills might be indirectly related to inner experience of pain due to high empathetic ability.

\section{Result of covariance structure analysis (hypothesized model)}

In addition to analyzing the relationship between social skills and pain sensitivity, we used structural equation modeling to reveal inter-relationships among the psychosociological factors such as psychological factors (loneliness and depression)

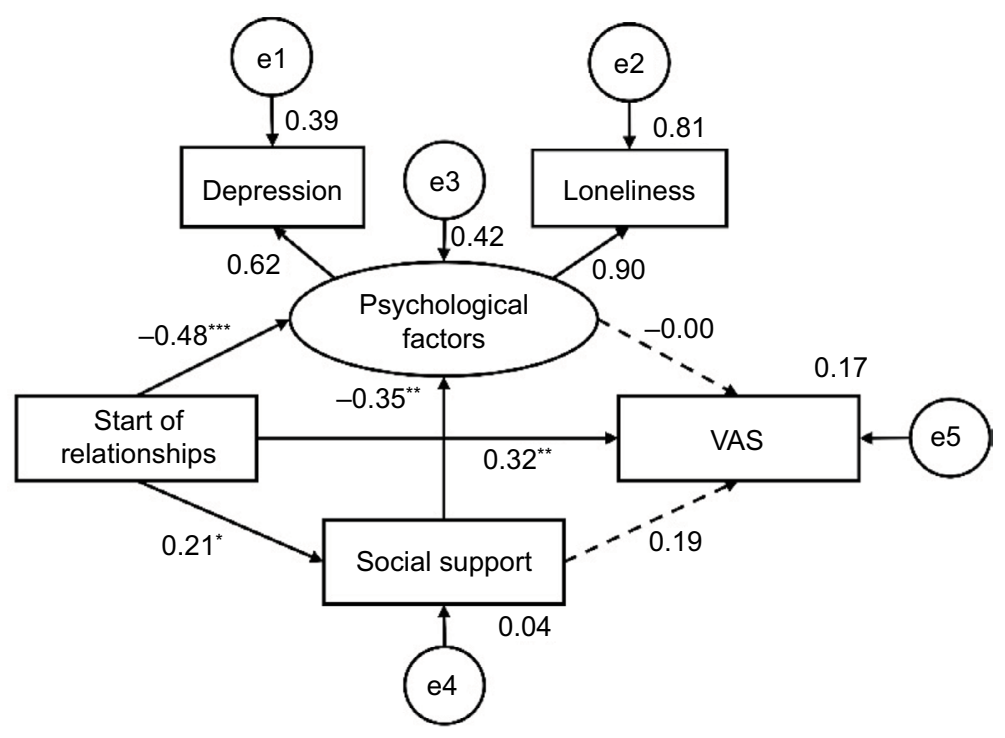

Figure 5 Modified model (nonsignificant paths are indicated by dotted lines).

Notes: Model fit indices: $\chi^{2}=0.446, d f=2, p=0.800$, goodness-of-fit index $(\mathrm{GFI})=0.998$, comparative fit index $(\mathrm{CFI})=1.000$, root mean squared error of the approximation $\left(\right.$ RMSEA) $=0.000 ;{ }^{*} p<0.05, *^{*} p<0.01,{ }^{* * *} p<0.001$.

Abbreviations: e, error; VAS, visual analog scale. 
and social support. In the hypothesized model, we designed a structural model that included each factor in addition to the relationships revealed by the correlational analysis and the results of a previous study which indicated that psychological factors (e.g., loneliness and depression) and social support were related to social skills. ${ }^{28-32}$

The hypothesized model specified that social skills had a direct effect on social support and psychological factors. Additionally, the psychological factors were directly affected by social skills and indirectly via social support. Thus, social skills were related to psychosociological factors in the present study as well as in the previous study, ${ }^{28-32}$ and it was revealed that individuals who have high social skills more readily received support from their neighbors and had more positive psychological condition. The previous study revealed a relationship between negative psychological condition and poor social support, ${ }^{49-52}$ and our hypothesized model corroborated the previous findings. However, there were no significant links between social skills and pain sensitivity, so the first hypothesized model did not clarify the relationship between social skill and pain sensitivity. Social skills encompass a wide variety of concepts and are multidimensional; therefore, many variabilities exist among elements in certain individuals. The variabilities among elements may have interfered with some significant relationships between social skills and pain sensitivity in the first hypothesized model.

In the correlational analysis, pain sensitivity was significantly correlated with partial subscales of the Social Skills Self-Rating Scale for Adults. Consequently, analyzing the correlations with the total value of social skill most likely attenuated the sensitivity of the scale to detect the relationship between social skills and pain sensitivity. Therefore, we modified the model, replacing social skills with the subscale "start of relationships" and refitted the structural equation model.

\section{Result of covariance structure analysis (modified model)}

We examined the modified model using the subscale "start of relationships," which showed the highest correlation coefficient with pain sensitivity. The result revealed that the relationships among "start of relationships," "social support," and "psychological factors" were the same as in the hypothesized model. A direct effect from "start of relationships" to pain sensitivity was observed. In other words, the value of "start of relationships" had a positive effect on pain sensitivity of inner experience.

The "start of relationships" subscale is comprised of eight items, such as "You're open with anyone," "You're friendly with anyone," "You start to have a conversation with a person who you've never met before," "I am good at talking with a person," "You readily join a conversation," "You readily greet anyone," "It's difficult to make a chance to start a conversation when you want to get to know a person," "You introduce yourself well to a person who you've never met before." The question picks out an extroverted personality trait, namely being sociable, whose association overflows into laughter and humor. ${ }^{53}$ A previous study also suggested that there is a strong relationship between social skills and extroversion; it clarified that extroversion becomes more prominent with higher level of social skills. ${ }^{54}$

In addition, previous studies revealed that high extroversion or high ability for empathy had significant relationships with low loneliness. ${ }^{28,55}$ In other words, high extroversion (i.e., high ability of start of relationships) was correlated with low levels of loneliness and high empathetic ability. In the modified model of this study, the "start of relationships" had negative effects on psychological factors and positive effects on pain sensitivity of inner experience. Therefore, "start of relationships," one of the subscales of the Social Skills Self-Rating Scale for Adults, might reflect extroversion, and high extroversion generally prevents fall into negative psychological conditions, and high empathetic ability appears to evoke high pain sensitivity from observations of painful scenes.

\section{Conclusion and limitations}

First, this study aimed to clarify the relationships between social skills and pain sensitivity. Second, we researched mutual intervals between social skills and pain sensitivity in addition to the psychosocial factors related to social skills. The result of correlation analysis showed significant positive correlations between VAS and total social skills values, as well as with the "start of relationships" subscales. Additionally, structural equation modeling revealed that "start of relationships" values had a direct effect on VAS values. The "start of relationships" had both a direct and an indirect effect via social support on the psychological factors. The social support had positive relationships with psychological factors but showed no significant links with VAS. Considering previous studies, ${ }^{19-23}$ similar tendency in the pain intensity of inner experience had been expected; however, social skills had positive effects on pain sensitivity of inner experience. Previous studies suggested that empathetic ability is strongly related to inner pain experiences that were induced by observing painful scenes. Therefore, the inner experience of pain might include an element of "the empathy of pain." 
The ability to empathize with others' experiences of negative feelings was thought to be important in constructing a good societal environment. ${ }^{56-58}$ These factors help us understand the relationship between social skills and the inner experience of pain. This is to say that the person who is easy to empathize with for the inner experience of pain has high social skills and is less likely to fall into depression; the person's interaction with the society is also likely to advance. We think that it is necessary to consider the influence of individual social skills for the clinical practice of pain in this study.

There are several limitations to this study. First, it showed no statistically significant differences between men and women in its measures. However, several studies have indicated that depression is more prevalent in women. ${ }^{59,60} \mathrm{It}$ is thought that representativeness of the sample collected in this study is related to these discrepancies. The sample used healthy volunteers, restricting generalizability to general and patient samples. Second, the Social Skills Self-Rating Scale for Adults, which we used as an evaluation of social skills, is mainly used in Japan, and only one reference exists. Finally, we estimated sensitivity to pain through an experimental procedure and self-reporting of the measured variables. We considered that the expectations of the experimenters had no influence, but we cannot completely deny this.

In the future, we will repeat this examination by including a measurement of objective social skills; it is necessary to compare the results of this study with those of a study on pain sensitivity in response to physical pain stimulation. Also, the psychological measures (depression, loneliness) that we used in this study have to observe the tendency in the clinical sample.

\section{Acknowledgments}

The abstract of this paper was presented at the 16th World Conference on Pain (2016) as a poster presentation with interim findings. The poster's abstract was published in "Poster Abstracts" in 16th World Congress on Pain website (https://event.crowdcompass.com/wcp2016).

\section{Disclosure}

The authors report no conflicts of interest in this work.

\section{References}

1. Schweinhardt P, Kalk N, Wartolowska K, et al. Investigation into the neural correlates of emotional augmentation of clinical pain. Neuroimage. 2008;40:759-766.

2. Kong J, Gollub RL, Rosman IS, et al. Brain activity associated with expectancy-enhanced placebo analgesia as measured by functional magnetic resonance imaging. J Neurosci. 2006;26:381-388.
3. Valet M, Sprenger T, Boecker H, et al. Distraction modulates connectivity of the cingulo-frontal cortex and the midbrain during pain-an fMRI analysis. Pain. 2004;109: 399-408.

4. Singer T, Seymour B, O'doherty J, Kaube H, Dolan RJ, Frith CD. Empathy for pain involves the affective but not sensory components of pain. Science. 2004;303:1157-1162.

5. Jackson PL, Meltzoff AN, Decety J. How do we perceive the pain of others? A window into the neural processes involved in empathy. Neuroimage. 2005;24:771-779.

6. Lamm C, Decety J, Singer T. Meta-analytic evidence for common and distinct neural networks associated with directly experienced pain and empathy for pain. Neuroimage. 2011;54:2492-2502.

7. Ogino Y, Nemoto H, Inui K, Saito S, Kakigi R, Goto F. Inner experience of pain: imagination of pain while viewing images showing painful events forms subjective pain representation in human brain. Cereb Cortex. 2007; 17:1139-1146.

8. Maeoka H, Matsuo A, Hiyamizu M, Morioka S, Ando H. Influence of transcranial direct current stimulation of the dorsolateral prefrontal cortex on pain related emotions: a study using electroencephalographic power spectrum analysis. Neurosci Lett. 2012;512(1):12-16.

9. Waddell G, Burton AK. Concepts of rehabilitation for the management of low back pain. Best Pract Res Clin Rheumatol. 2005;19(4):655-670.

10. Macdonald G, Leary MR. Why does social exclusion hurt? The relationship between social and physical pain. Psychol Bull. 2005;131:202-223.

11. Jackson JC, Santoro MJ, Ely TM, et al. Improving patient care through the prism of psychology: application of Maslow's hierarchy to sedation, delirium and early mobility in the ICU. J Crit Care. 2014; 29(3):438-444

12. Eisenberger NI, Lieberman MD, Williams KD. Does rejection hurt? An FMRI study of social exclusion. Science. 2003;302(5643):290-292.

13. Hartgerink $\mathrm{CH}$, van Beest I, Wicherts JM, Williams KD. The ordinal effects of ostracism: a meta-analysis of 120 Cyberball studies. PLoS One. 2015;10(5):e0127002.

14. Eisenberger NI. The neural bases of social pain: evidence for shared representations with physical pain. Psychosom Med. 2012;74(2):126-135.

15. Kross E, Berman MG, Mischel W, Smith EE, Wager TD. Social rejection shares somatosensory representations with physical pain. Proc Natl Acad Sci USA. 2011;108(15):6270-6275.

16. Gatchel RJ. Comorbidity of chronic pain and mental health disorders: the biopsychosocial perspective. Am Psychol. 2004;59(8):795-805.

17. Gatchel RJ, Peng YB, Peters ML, Fuchs PN, Turk DC. The biopsychosocial approach to chronic pain: scientific advances and future directions. Psychol Bull. 2007; 133(4):581-624.

18. Vigil JM, Rowell LN, Chouteau S, al. Sex differences in how social networks and relationship quality influence experimental pain sensitivity. PLoS One. 2013;8(11):e78663.

19. Eisenberger NI, Master SL, Inagaki TK, et al. Attachment figures activate a safety signal-related neural region and reduce pain experience. Proc Natl Acad Sci USA. 2011;108(28):11721-11726.

20. Brown JL, Sheffield D, Leary MR, Robinson ME. Social support and experimental pain. Psychosom Med. 2003;65(2):276-283.

21. Onoda K, Okamoto Y, Nakashima K, Nittono H, Ura M, Yamawaki S. Decreased ventral anterior cingulate cortex activity is associated with reduced social pain during emotional support. Soc Neurosci. 2009;4(5): 443-454.

22. Younger J, Aron A, Parke S, Chatterjee N, Mackey S. Viewing pictures of a romantic partner reduces experimental pain: involvement of neural reward systems. PLoS One. 2010;5(10):e13309.

23. Jaremka LM, Fagundes CP, Glaser R, Bennett JM, Malarkey WB, Kiecolt-Glaser JK. Loneliness predicts pain, depression, and fatigue: understanding the role of immune dysregulation. Psychoneuroendocrinology. 2013;38(8):1310-1317.

24. Tamrin SB, Yokoyama K, Jalaludin J, et al. The association between risk factors and low back pain among commercial vehicle drivers in peninsular Malaysia: a preliminary result. Ind Health. 2007;45(2): $268-278$. 
25. Shuchang H, Mingwei H, Hongxiao J, et al. Emotional and neurobehavioural status in chronic pain patients. Pain Res Manage. 2011;16(1): $41-43$.

26. Segrin C. Specifying the nature of social skill deficits associated with depression. Hum Commun Res. 1992;19:89-123.

27. Liberman RP. Assessment of social skills. Schizophr Bull. 1982;8: 62-83.

28. Beadle JN, Brown V, Keady B, Tranel D, Paradiso S. Trait empathy as a predictor of individual differences in perceived loneliness. Psychol Rep. 2012;110(1):3-15.

29. Wierzbicki M, McCabe M. Social skills and subsequent depressive mood symptomatology in children. J Clin Child Psychol. 1988;17: 203-208.

30. Cole DA, Milstead M. Behavioral correlates of depression: antecedents or consequences? J Couns Psychol. 1989;36:408-416.

31. Cohen S, Sherrod DR, Clark MS. Social skills and the stress-protective role of social support. J Pers Soc Psychol. 1986;50(5):963-973.

32. Müller R, Peter C, Cieza A, et al. Social skills: a resource for more social support, lower depression levels, higher quality of life, and participation in individuals with spinal cord injury? Arch Phys Med Rehabil. 2015;96(3):447-455.

33. Cohen J. Statistical Power Analysis for the Behavioral Sciences. 2nd ed. Hillsdale (NJ): Lawrence Earlbaum Associates; 1988.

34. Pelentsov LJ, Fielder AL, Laws TA, Esterman AJ. Development of the parental needs scale for rare diseases: a tool for measuring the supportive care needs of parents caring for a child with a rare disease. J Multidiscip Healthc. 2016;9:425-33.

35. Kassab SE, Al-Shafei AI, Salem AH, Otoom S. Relationships between the quality of blended learning experience, self-regulated learning, and academic achievement of medical students: a path analysis. Adv Med Educ Pract. 2015;6:27-34.

36. Lewis-Beck C, Abouzaid S, Xie L, Baser O, Kim E. Analysis of the relationship between psoriasis symptom severity and quality of life, work productivity, and activity impairment among patients with moderateto-severe psoriasis using structural equation modeling. Patient Prefer Adherence. 2013;7:199-205.

37. Jackson PL, Brunet E, Meltzoff AN, Decety J. Empathy examined through the neural mechanisms involved in imagining how I feel versus how you feel pain. Neuropsychologia. 2006;44:752-761.

38. Buruck G, Wendsche J, Melzer M, Strobel A, Dörfel D. Acute psychosocial stress and emotion regulation skills modulate empathic reactions to pain in others. Front Psychol. 2014;30(5):517.

39. Katz J, Melzack R. Measurement of pain. Surg Clin North Am. 1999;79(2):231-252.

40. Hawker GA, Mian S, Kendzerska T, French M. Measures of adult pain: visual analog scale for pain (VAS pain), numeric rating scale for pain (NRS pain), McGill pain questionnaire (MPQ), short-form McGill pain questionnaire (SF-MPQ), chronic pain grade scale (CPGS), short form-36 bodily pain scale (SF-36 BPS), and measure of intermittent and constant osteoarthritis pain (ICOAP). Arthritis Care Res (Hoboken). 2011;63(11):S240-S252.
41. Aikawa A, Fujita M. [An attempt to construct a social skills self-rating scale for adults]. Bull Tokyo Gakugei Univ (Series I, Science of Education). 2005;56:87-93. Japanese.

42. Zimet G, Dahlem N, Zimet S, Farley G. The multidimensional scale of perceived social support. J Pers Assess. 1988;52:30-41.

43. Kojima M, Furukawa TA, Takahashi H, Kawai M, Nagaya T, Tokudome S. Cross-cultural validation of the Beck Depression Inventory-II in Japan. Psychiatry Res. 2002;110:291-299.

44. Arnau RC, Meagher MW, Norris MP, Bramson R. Psychometric evaluation of the Beck Depression Inventory-II with primary care medical patients. Health Psychol. 2001;20:112-119.

45. Russell D, Peplau LA, Ferguson ML. Developing a measure of loneliness. J Pers Assess. 1978;42:290-294.

46. Russell D, Peplau LA, Cutrona CE. The revised UCLA Loneliness Scale: concurrent and discriminant validity evidence. J Pers Soc Psychol. 1980;39:472-480.

47. Moroi, H. [Dimensions of the revised UCLA Loneliness Scale]. Jinbun Ronsyu. 1991;42:23-51. Japanese.

48. Byme BM. Structural Equation Modeling with AMOS-Basic Concepts, Applications, and Programming. Mahwah (NJ): Lawrence Erlbaum Associates Inc; 2001.

49. Moriguchi Y, Decety J, Ohnishi T, et al. Empathy and judging other's pain: an fMRI study of alexithymia. Cereb Cortex. 2007;17(9):2223-2234.

50. Pollard C, Kennedy P. A longitudinal analysis of emotional impact, coping strategies and post-traumatic psychological growth following spinal cord injury: a 10-year review. Br J Health Psychol. 2007;12(Pt 3):347-362.

51. Stroud MW, Turner JA, Jensen MP, Cardenas DD. Partner responses to pain behaviors are associated with depression and activity interference among persons with chronic pain and spinal cord injury. J Pain 2006;7(2):91-99.

52. Elfström M, Rydén A, Kreuter M, Taft C, Sullivan M. Relations between coping strategies and health-related quality of life in patients with spinal cord lesion. J Rehabil Med. 2005;37(1):9-16.

53. Eysenck HJ, Eysenck SBG. Manual of the Eysenck Personality Questionnaire (junior and adult). London: Hodder and Stoughton; 1975.

54. Argyle M, Lu L. Happiness and social skills. Pers Individ Dif. 1990;11(12):1255-1261.

55. Kong X, Wei D, Li W, et al. Neuroticism and extraversion mediate the association between loneliness and the dorsolateral prefrontal cortex. Exp Brain Res. 2015;233(1):157-164.

56. Batson CD, Batson JG, Slingsby JK, Harrell KL, Peekna HM, Todd RM. Empathic joy and the empathy-altruism hypothesis. J Pers Soc Psychol. 1991;61(3):413-426.

57. Eisenberg N, Miller PA. The relation of empathy to prosocial and related behaviors. Psychol Bull. 1987;101(1):91-119.

58. Sifneos PE. The prevalence of "alexithymic" characteristics in psychosomatic patients. Psychother Psychosom. 1973;22(2):255-262.

59. Albert PR. Why is depression more prevalent in women? J Psychiatry Neurosci. 2015;40(4):219-221.

60. Kawakami N. [Epidemiology of depressive disorders in Japan and the world]. Nihon Rinsho. 2007;65(9):1578-1584. Japanese.
Journal of Pain Research

\section{Publish your work in this journal}

The Journal of Pain Research is an international, peer reviewed, open access, online journal that welcomes laboratory and clinical findings in the fields of pain research and the prevention and management of pain. Original research, reviews, symposium reports, hypothesis formation and commentaries are all considered for publication.
The manuscript management system is completely online and includes a very quick and fair peer-review system, which is all easy to use. Visit http://www.dovepress.com/testimonials.php to read real quotes from published authors. 